Article type : Original Articles

Editor $\quad$ : Christophe Bureau

\title{
ADIPOPENIA CORRELATES WITH HIGHER PORTAL PRESSURE IN PATIENTS WITH CIRRHOSIS
}

Susana G. Rodrigues ${ }^{1 * 2}$, Ben Brabandt ${ }^{3^{*}}$, Guido Stirnimann ${ }^{1}$, Martin H. Maurer ${ }^{3^{* *}}$, Annalisa Berzigotti ${ }^{1^{* *}}$

${ }^{1}$ Swiss Liver Center, UVCM, Inselspital, Bern University Hospital, Department of Biomedical Research, University of Bern, Switzerland; ${ }^{2}$ Faculty of Medicine of the University of Porto, Portugal, ${ }^{3}$ Radiology, Inselspital, Bern University Hospital, University of Bern, Switzerland;

${ }^{*}$ This denotes co-first authorship. ${ }^{* *}$ This denotes co-senior authorship.

\section{Correspondence:}

Annalisa Berzigotti, MD, PhD;

Address: Swiss Liver Center, Hepatology, University Clinic for Visceral Surgery and Medicine, Inselspital, Department of Biomedical Research, University of Bern

This article has been accepted for publication and undergone full peer review but has not been through the copyediting, typesetting, pagination and proofreading process, which may lead to differences between this version and the Version of Record. Please cite this article as doi: $10.1111 /$ liv. 14175

This article is protected by copyright. All rights reserved. 
MEM F807, Murtenstrasse 35, CH - 3008 Berne, Switzerland

Tel. +41 3163287 27; Fax. +4131632 4997

E-mail: annalisa.berzigotti@insel.ch

\section{Abbreviations}

AlH autoimmune hepatitis

ALD alcoholic liver disease

APRI $\quad$ AST platelet ratio index

AUROC area under the receiver operating curve

BMI body mass index

$\mathrm{Cl} \quad$ confidence interval

$\mathrm{CSPH} \quad$ clinically significant portal hypertension

CT computed tomography

HBV hepatitis B virus

HCC hepatocellular carcinoma

HCV hepatitis $\mathrm{C}$ virus

HR hazard ratio

HVPG Hepatic venous pressure gradient

HU Houndsfield unit

INR international normalized ratio

IMATI intramuscular adipose tissue index

IQR interquartile range

L3 third lumbar vertebra

LSPS liver stiffness ${ }^{*}$ spleen size over platelets risk score

MELD Model for End-Stage Liver Disease 


$\begin{array}{ll}\text { MELD-Na } & \text { MELD -Sodium model } \\ \text { MRI } & \text { magnetic resonance imaging } \\ \text { NAFLD } & \text { Nonalcoholic fatty liver disease } \\ \text { NASH } & \text { nonalcoholic steatohepatitis } \\ \text { PBC } & \text { primary biliary cirrhosis } \\ \text { PMI } & \text { psoas muscle index } \\ \text { PSC } & \text { primary sclerosing cholangitis } \\ \text { SATI } & \text { subcutaneous adipose tissue index } \\ \text { SMI } & \text { skeletal muscle index } \\ \text { TATI } & \text { total adipose tissue index } \\ \text { TIPS } & \text { transjugular intrahepatic portosystemic shunt } \\ \text { VATI } & \text { visceral adipose tissue index }\end{array}$

\section{Statement of author contributions:}

SGR: compilation and analysis of the data and drafting the manuscript; BB: compilation of data and manuscript revision; GS: study conception and manuscript revision; MHM: study conception, compilation of data and manuscript revision; AB: study conception, analysis and compilation of data and drafting of manuscript.

All authors have commented on the manuscript and approved the final version.

\section{Disclosures:}

The authors have no potential conflicts (financial, professional, or personal) that are relevant to the manuscript to disclose. 


\title{
Acknowledgement:
}

Susana G. Rodrigues receives financial support from the Stiftung für Leberkrankheiten Bern.

\begin{abstract}
Background \& Aims. In cirrhosis, hepatic venous pressure gradient (HVPG) and imaging body composition assessment can influence prognosis. We assessed whether adipose and skeletal muscle tissue reflect the severity of portal hypertension $(\mathrm{PH})$, and whether they improve non-invasive prediction of decompensation and death.
\end{abstract}

Methods: We included 84 cirrhosis patients with HVPG and computed tomography (CT) within 12 weeks of HVPG at a single centre. L3 vertebra CT images were used for body composition indexes $\left(\mathrm{cm}^{2} / \mathrm{m}^{2}\right)$ : total adipose tissue index (TATI), visceral adipose tissue index (VATI), subcutaneous adipose tissue index (SATI), intramuscular adipose tissue index (IMATI), skeletal muscle index (SMI) and psoas muscle index (PMI). Correlations were calculated between indexes, HVPG and standard non-invasive tests for $\mathrm{PH}$. 12-month decompensation and death predictors were determined.

Results: Male $61 \%$; BMI $28 \pm 5 \mathrm{~kg} / \mathrm{m}^{2}$; alcoholic liver disease in $51 \%$, non-alcoholic steatohepatitis in 24\%; HVPG $14 \pm 6 \mathrm{mmHg}$; $45 \%$ compensated. Median follow-up was 11 (4-17) months. HVPG correlated with SATI $(r=-0.282, \mathrm{p}=0.01)$, TATI ( $r=-$ $0.220, \mathrm{p}=0.045)$ and SATI/VATI index $(r=-0.240, \mathrm{p}=0.03)$. In compensated patients, lower VATI (HR 0.94 (0.90-0.99), p=0.01) was associated with 12-month 
decompensation. Combining TATI and liver stiffnessxspleen size over-platelet count risk score (LSPS) added discriminative capacity for 12-month decompensation (AUROC 0.91 vs. 0.87). IMATI was independently associated with mortality in decompensated patients. MELD-Na combined with IMATI discriminated excellently for mortality (AUROC 0.94; $p<0.001)$.

Conclusions: HVPG inversely correlates with imaging markers of adipose tissue, while markers of sarcopenia were unrelated to PH. In compensated patients, TATI improves non-invasive prediction of decompensation. In decompensated patients, IMATI independently predicted mortality.

Keywords: advanced chronic liver disease; body composition; portal hypertension; computed tomography;

\section{Lay summary}

We assessed whether fat and muscle tissue reflect the severity of portal vein pressure and whether it improves non-invasive prediction of decompensation and death in patients with liver cirrhosis. Portal pressure inversely correlates with imaging markers of fat tissue, while markers of muscle wasting were unrelated to portal pressure. In compensated patients, total fat index improves non-invasive prediction of decompensation. In decompensated patients, fatty infiltration of muscle independently predicted mortality. Although further validation of these findings is needed, our findings suggest that on CT-based body composition assessment 
muscle and fat compartments should be taken into account to allow an appropriate risk stratification for decompensation and death in cirrhosis.

\section{Introduction}

Risk stratification in patients with cirrhosis is paramount to achieve a personalized, pathophysiology stage-oriented approach. ${ }^{1}$ Well-established prognostic markers in cirrhosis include liver function (albumin, bilirubin, International Normalized Ratio, Model for End-stage Liver Disease score), presence of complications (ascites, gastro-oesophageal varices) and hepatic venous pressure gradient (HVPG), the accepted equivalent of portal pressure. ${ }^{2}$ In compensated patients, HVPG is the single best prognostic factor, and it has been associated with the risk of developing varices, first clinical decompensation and hepatocellular carcinoma. ${ }^{2,3}$ In decompensated patients, HVPG predicts recurrent variceal bleeding and survival. ${ }^{2,4}$ Over the last years, nutritional status and body composition have emerged as determinants of outcome in cirrhosis and are gaining increasing attention. ${ }^{5}$ Importantly, these can be explored non-invasively in patients with cirrhosis by measuring adipose tissue and skeletal muscle components on cross-sectional imaging, such as computed tomography (CT). ${ }^{6,711}$ Sarcopenia - a reduction in skeletal muscle mass - has been proven associated with worse prognosis in patients with decompensated cirrhosis. ${ }^{12-15}$ Recently fat tissue depletion - adipopenia - has been additionally associated with higher mortality in women with cirrhosis. ${ }^{15}$ 
Inflammation underlying to changes in body composition in patients with cirrhosis could be potentially due in part to portal hypertension, and vice-versa, the inflammatory crosstalk between fat, muscle and the liver occurring in cirrhosis could lead to an increase in portal pressure. ${ }^{16}$ Until date, no study has specifically evaluated the relationship between HVPG and imaging markers of adipose tissue and skeletal muscle in patients with cirrhosis, and whether body composition on imaging and portal pressure should be considered independent prognostic markers. Our study aimed at addressing these questions.

\section{Methods}

\section{Study Population and endpoints}

All consecutive patients ( $\geq 18$ years) who underwent measurement of HVPG and TJLB between January 2015 and March 2018 were screened for the inclusion in this study.

We included those fulfilling all the following criteria: a) histologically proven cirrhosis, b) abdominal computed tomography (CT) within (before or after) 12 weeks of HVPG measurement, and c) clinical follow-up at our centre. Exclusion criteria were: absence of cirrhosis on histology, malignancy (including HCC), or end-stage heart, kidney or lung disease (see flowchart Supplementary Figure 1). 
HVPG and TJLB were indicated to further characterize liver disease. CT scan was performed for HCC screening in patients unsuitable for ultrasound assessment, in the context of further characterization of patients on first diagnosis or decompensation, or as a routine workup for inclusion for the liver transplantation waiting list. Baseline clinical and laboratory data were determined on the day of HVPG measurement. Patients were considered "compensated" on inclusion if no episode of clinical decompensation (ascites, variceal bleeding, hepatic encephalopathy) was present in the past or on inclusion.

The selection of patients was performed by two hepatologists, blinded to CT findings. The evaluation of body composition markers on CT images was performed at the end of the patient selection by an expert radiologist blinded to the patients' clinical data, including HVPG value.

Patients were followed-up until end of September 2018. First or subsequent episodes of clinical decompensation (oesophago-gastric variceal bleeding, ascites, hepatic encephalopathy, spontaneous bacterial peritonitis or hepatorenal syndrome), liver-related death and transplantation were collected. Portal vein thrombosis, HCC or other cancer onset in the absence of clinical decompensation $(n=3)$ were not considered as "decompensation" of cirrhosis. Patients lost to follow-up were censored for at the date of the last visit. 
All patients provided informed written consent to the HVPG procedure and signed the general consent form for the use of their health-related data. The Canton of Bern Research Ethics Committee (KEK 2018-00487) approved the study.

\section{Clinical Data collection}

Baseline patients' characteristics such as demographical data (age, gender), aetiology, medication, history of liver disease, Child-Pugh and MELD scores, laboratory, ultrasonographic and endoscopic findings were collected from the hospital's electronic database. Liver stiffness (LS) values were obtained using transient elastography. Liver stiffness $\mathrm{x}$ spleen diameter to platelet ratio (LSPS) was calculated as follows: LS value * spleen diameter/platelet count. ${ }^{17}$

\section{Hemodynamic study and transjugular liver biopsy}

On fasting conditions and under local anaesthesia, a 9F venous catheter introducer (Radiofocus Introducer II, Terumo, Japan) was placed in the right jugular vein (in one case: left jugular vein) under ultrasonographic guidance (SonoSite Inc, Bothell, WA, USA) using the Seldinger technique. Under pulsed fluoroscopy control, a 5 or $6 \mathrm{~F}$ multipurpose catheter (Tempo 5 or 6 MPA1, Cordis, Ireland) was advanced into a main hepatic vein of the right lobe with the help of a hydrophilic guidewire (Radiofocus Guidewire M Stiff type angled, Terumo, Japan). A 6F balloon-tipped catheter (Cook Medical, Bloomington, IN, USA) was then used to measure hepatic venous pressures (Pressure transducer: Xtrans, CODAN Pvb Critical Care GmbH, Forstinning, Germany). Free hepatic venous pressure was measured by maintaining 
the tip of the catheter free in the hepatic vein at $2-4 \mathrm{~cm}$ from its opening into the vena cava inferior. Wedged hepatic venous pressure was measured by occluding the hepatic vein by inflating the balloon at the tip of the catheter. All measurements were taken as triplicates and permanent tracings were obtained with a multichannel recorder (Sensis Dialog, Siemens Healthcare GmbH, Erlangen, Germany). Portal hypertension was classified as subclinical if HVPG was 6-9 mm Hg and clinically significant if $\geq 10 \mathrm{~mm} \mathrm{Hg}$. Very severe portal hypertension was diagnosed if HVPG $\geq$ $16 \mathrm{~mm} \mathrm{Hg}$, due to its associated increased risk of mortality. ${ }^{2}$

After the measurements, $2 \mathrm{~mL} I \mathrm{ICM}$ were injected to confirm that the anatomy and size of the hepatic vein was appropriate to perform liver biopsy. Transjugular liver biopsy was performed as previously described. ${ }^{18}$

\section{CT evaluation}

Imaging biomarkers of body composition included skeletal muscle (SM), and adipose tissues (visceral-VAT; intramuscular-IMAT and subcutaneous-SAT). These were measured by analysis of CT images at the level of the third lumbar (L3) vertebra by using a semi-automatic software (SliceOmatic ${ }^{\mathrm{TM}} \vee$ 5.0, Tomovision, Montreal, Quebec, Canada). The cross-sectional area of skeletal muscles and subcutaneous or visceral adipose tissue were measured in units of squared centimetres. Skeletal muscles assessed included the psoas, erector spinae, quadratus lumborum, transversus abdominis, external and internal obliques, and rectus abdominis muscles. The different tissue types were selected by using tissue-specific Hounsfield 
unit (HU) thresholds. The CT HU thresholds were -29 to 150 for skeletal muscles ${ }^{7}$ 190 to -30 for subcutaneous adipose tissue, and -150 to -50 for visceral adipose tissue. Using these HUs, adipose tissue within the abdominal wall was quantified as visceral adipose tissue. The subcutaneous adipose tissue cross-sectional area was estimated as the area between the skin line and outer abdominal wall. ${ }^{8-11}$ Values were normalized for stature in squared meters and results are provided as indexes (I) as follows: skeletal muscle index (SMI), psoas muscle index (PMI), total adipose tissue index (TATI), subcutaneous adipose tissue index (SATI), and visceral adipose tissue index (VATI) in units of centimetres squared/meters squared. Intramuscular adipose tissue index (IMATI) was similarly. ${ }^{19}$ Sarcopenia was diagnosed using cutoffs previously published in Western population of liver transplant candidates of an L3 muscle area normalized to height (SMI) of $50 \mathrm{~cm}^{2} / \mathrm{m}^{2}$ for men and $39 \mathrm{~cm}^{2} / \mathrm{m}^{2}$ for women). ${ }^{20}$ Subcutaneous adipopenia $\left(\mathrm{SATI}<60 \mathrm{~m}^{2} / \mathrm{cm}^{2}\right.$ ) was previously associated with mortality in patients with cirrhosis. ${ }^{15}$ SATI over VATI index reflected the relationship between visceral and subcutaneous adipose tissue.

\section{Statistical analysis}

Continuous variables are presented as both as mean and standard deviation (SD) and in median and interquartile range. $T$-test for independent sample was used to compare differences in means. For categorical variables, descriptive statistics are presented as frequency and percentages and the comparison between study groups was conducted using Pearson chi-squared test. Correlations between body composition markers and HVPG were determined by either Pearson's correlation coefficient $(r)$ or Spearman's rho coefficient analysis. When assessing mortality and decompensation, patients were censored at the time of the last visit. Significant 
predictors of mortality and decompensation were determined using univariate and multivariate Cox proportional hazard models and the results were reported as hazard ratios $(\mathrm{HR})$ and $95 \%$ confidence intervals $(\mathrm{Cl})$. To avoid overfitting on multivariate analysis, 1 variable per 5 events was entered into the model. ${ }^{21}$ For the model predicting mortality, MELD-Na was chosen because it incorporated the most significant parameters in univariate analysis, thereby avoiding collinearity. Areas under the operating receiver curve (AUROC) were calculated to determine the discriminative ability of HVPG and non-invasive tests for decompensation and death. Data were analysed using SPSS (version 25; IBM, Armonk, NY). A sub-analysis for gender was conducted. A P value $<0.05$ was considered statistically significant.

\section{Results}

The general baseline characteristics of the 84 patients fulfilling the inclusion criteria are shown in Table 1. Fifty-one patients were male (61\%) with a mean age of $57 \pm 11$ years. In $75 \%$ of the cases, the patients had either alcohol-related or metabolic syndrome-associated cirrhosis, or both. In fact, the majority of patients were overweight with a mean BMI of $28 \pm 5 \mathrm{Kg} / \mathrm{m}^{2}$. The mean Child-Pugh and MELD scores were similar in both genders. Thirty-eight patients (45\%) were fully compensated at the time of HVPG measurement. Among the 46 (55\%) decompensated patients 32 had ascites, 8 had hepatic encephalopathy and 6 had a recent episode of variceal bleeding. $13 \%$ had decompensated within a month prior to the HVPG measurement. The overall mean HVPG was $14.0 \pm 6 \mathrm{~mm} \mathrm{Hg}$, similar for male compared to female patients with $14.5 \pm 6$ vs. $13.3 \pm 6 \mathrm{~mm} \mathrm{Hg}(p=0.39)$. Median follow-up time (IQR) was 11 (4-18) months. 
Seven out of the 38 patients (18\%) with compensated cirrhosis presented a first episode of clinical decompensation in the follow-up. Sixteen patients (19\%) died (death in $24 \%$ men vs. $12 \%$ women; $p=0.26$ ). The causes of death were as follows: liver failure (8), sepsis (4), HCC (2), cholangiocarcinoma (1) and 1 of unclear cause.

\section{Body composition analysis}

The mean BMI was for males: $29 \pm 6 \mathrm{~kg} / \mathrm{m}^{2}$ and females: $28 \pm 5 \mathrm{~kg} / \mathrm{m}^{2}$ (Supplementary Table 1). Among males and females the prevalence of sarcopenia, using the established cut-offs were: $69 \%$ and $45 \%$, respectively ( $p=0.04$ ). VATI was higher for males $71 \pm 34$ vs. $48 \pm 26 \mathrm{~cm}^{2} / \mathrm{m}^{2}(p=0.001)$.

Notably, VATI was significantly higher in alcoholic liver disease (ALD) and nonalcoholic fatty liver disease (NAFLD) versus other aetiologies $(p=0.048)$. Patients with previous or ongoing decompensation and MELD score $\geq 16$ had significantly lower SATIs compared to compensated patients ( $p=0.04$ and $p=0.048$, respectively) (Figure 1).

\section{Correlation of imaging body composition markers and HVPG}

No significant correlation was found between HVPG and SMI or PMI, nor with sarcopenia (Table 2). On the other hand, HVPG showed significant inverse correlations with adipose tissue indexes: SATI $(r=-0.282, \mathrm{p}=0.01), \mathrm{TATI}(r=-0.220$, $\mathrm{p}=0.045)$ and SATI-over-VATI index $(r=-0.240, \mathrm{p}=0.03)$. 
As shown in Table 3, SATI was lower in patients with higher HVPG: $91 \pm 47 \mathrm{~cm}^{2} / \mathrm{m}^{2}$ in patients with subclinical portal hypertension, $72 \pm 40 \mathrm{~cm}^{2} / \mathrm{m}^{2}$ in patients with HVPG $10-12 \mathrm{mmHg}\left(p=0.028\right.$ vs. subclinical) and $65 \pm 33 \mathrm{~cm}^{2} / \mathrm{m}^{2}(p=0.028$ vs. subclinical) in patients with $\mathrm{HVPG} \geq 16 \mathrm{mmHg}$ (very severe $\mathrm{PH}$ ).

\section{Correlation of HVPG with imaging body composition markers, and other non-} invasive markers of portal hypertension

In the current study population, LSPS correlated well with the HVPG $(r=0.65$, $\mathrm{p}<0.001$ ) (Suppl. Table 2). The strength of the correlation was particularly strong in women $(r=0.84, \mathrm{p}<0.001)$ and in patients with aetiologies other than ALD or NAFLD $(r=0.82, \mathrm{p}<0.001)$.

Patients with compensated cirrhosis: Factors associated with the risk of first decompensation at 12 months

Table 4 shows the univariate analysis of factors associated with first clinical decompensation at 12 months. As shown, LS, platelet count, their combination into the LSPS, HVPG and CT fat compartment areas TATI and VATI and their ratio were associated with this outcome. Given the low number of events, Cox multivariate regression analysis was limited to 2 variables at a time. LSPS (which included 2 of the significant variables in univariate analysis: LS and platelet count) was tested in a model with each: TATI, VATI and SATI/VATI. Among the three, TATI was the strongest in the model combining LSPS. Therefore, LSPS combined with TATI constitutes our final model. 
As for the discriminative ability of non-invasive tests for predicting clinical decompensation, liver stiffness had an AUROC of $0.77(95 \% \mathrm{Cl} 0.57-0.98, \mathrm{p}=0.04)$, AST to platelet ratio index (APRI) of $0.84(95 \% \mathrm{Cl} 0.66-0.99 \mathrm{p}=0.01)$, LSPS of 0.87 $(95 \% \mathrm{Cl} 0.74-0.99, \mathrm{p}=0.004)$ and LSPS-TATI of $0.91(95 \% \mathrm{Cl} 0.80-0.99, \mathrm{p}=0.002)$ (Figure 2).

\section{Factors associated with 12-month mortality}

The mortality rate in our population was relatively low ( $n=16$ events at 12 months; $19 \%$ ) and occurred exclusively in decompensated patients. In univariate analysis the significant variables associated with death included: age, bilirubin, MELD, Na, ChildPugh, TATI, VATI and IMATI. Cox regression analysis was limited to 3 variables at a time, given the low number of events. As MELD, Child-Pugh and bilirubin were collinear, the strongest one, MELD, was selected and MELD-Na was calculated, as Na was a significant variable. The variables VATI and IMATI were collinear with TATI and so the strongest, IMATI (HR 1.14, 95\% Cl, 1.06-1.23, $\mathrm{P}=0.001)$ for both males and females, was chosen. Therefore, MELD-Na combined with IMATI constitutes our final model. As compared to standard scores predicting mortality, the combination of MELD-Na-IMATI was superior to Child-Pugh, MELD 0.85 (95\%CI 0.72-0.97, $p=0.001$ ) and MELD-Na scores (Figure 2).

\section{Discussion}

This is the first study analysing the relationship between portal pressure and both fat and muscle body composition markers in a Western cohort of well-characterized patients with compensated and decompensated cirrhosis. A previous study 
conducted in Asia showed that psoas muscle area was an independent predictor for long-term mortality in cirrhotic patients with ascites, but showed no significant correlation between HVPG and psoas muscle thickness index. ${ }^{22}$ Recently, another Asian group studied the impact of sarcopenia on mortality in compensated and earlydecompensated patients with cirrhosis and HVPG measurements, in a distinct population from ours, showing no correlation between HVPG and sarcopenia. ${ }^{23}$

In the present study, in addition to muscle, we evaluated fat compartments, and our patients were histologically diagnosed with cirrhosis. In our cohort, we confirm no association between muscle mass and HVPG; however, we could demonstrate that HVPG significantly and inversely correlated with SATI particularly in females, decompensated patients and those with ALD or NASH cirrhosis. In patients with a very high HVPG value ( $\geq 16 \mathrm{mmHg})$, which indicates a higher risk of death ${ }^{2}, \mathrm{SATI}-$ but not VATI - was much lower than in patients with earlier stages of portal hypertension. The depletion of the TATI also significantly correlated with HVPG, and was particularly important among patients with sarcopenia.

These findings highlight that, while muscle depletion shows no relationship with portal pressure itself, fat loss and portal hypertension are related. Until very recently, attention has been focused on sarcopenia; however, the importance of VAT abundance and SAT depletion has become a matter of interest. ${ }^{24,25}$ Subcutaneous adipose tissue is the metabolically more favourable fat compartment ${ }^{26}$, and, in most patients, the most abundant within total adipose tissue. From a clinical point of view, it has been observed that a healthy amount of SAT may imply a survival benefit. ${ }^{26}$ Specifically, among women with cirrhosis, it was hypothesized that higher SAT 
allowed these patients to endure weight losses and subsequent longer overall surviva ${ }^{15}$; similar findings have been shown in patients with cancer. ${ }^{27}$ In animal models, the removal of subcutaneous fat is associated with increase in visceral fat mass, insulin resistance, circulating insulin, and TNF-a. ${ }^{28}$ These changes imply a pro-inflammatory state that could negatively influence the progression of cirrhosis and portal hypertension. Recent evidence in animal models of cirrhosis ${ }^{29,30}$ and in patients with cirrhosis and obesity undergoing an intensive life-style intervention support that improvement in the adipokine profile could improve portal hypertension. ${ }^{31}$ Whether achieving an increase in SAT could represent a strategy to modulate favourably portal pressure remains a field for future research.

Besides confirming that a clear sex difference exists, as for the prognostic meaning of fat depletion, our findings suggest that the relationship between body composition markers and severity of portal hypertension are aetiology-dependent. In our cohort, there was a clear predominance of patients with ALD and NAFLD, accounting for $75 \%$ of patients, which differentiates our population from most previous studies, largely including patients with viral hepatitis and patients with HCC. Additionally, the mean visceral adipose tissue compartment, VATI, was higher than in previously reported series (mean VATI $62 \pm 33 \mathrm{~cm}^{2} / \mathrm{m}^{2}$ in our cohort vs. $<40 \mathrm{~cm}^{2} / \mathrm{m}^{2}$ in previous cohorts). ${ }^{15}$

Regarding prognosis, the inclusion of compensated patients provides an insight into the prevalence and disparities in body composition among different stages of cirrhosis, which are key to guide management. ${ }^{1}$ Unsurprisingly, sarcopenia and significant adipopenia, and particularly SAT depletion, were more common in 
decompensated patients. However, about $20 \%$ of fully compensated patients showed features of subcutaneous adipopenia, highlighting a group of increased risk of progression that could be likely susceptible to early intervention.

Furthermore, we addressed the relationship between body composition markers and first clinical decompensation, which is the most important endpoint in compensated patients. ${ }^{1}$ Regarding this, we found that in addition to expected factors, such as HVPG, platelet count and liver stiffness, the presence of fat depletion, in all compartments, was significantly associated with first clinical decompensation. Combining the liver stiffness-spleen size-over-platelet risk score (LSPS) to the total adipose tissue index (TATI) lead to a new completely non-invasive index that could predict decompensation with an AUROC of 0.91 (Figure 2), strongly suggesting that both factors should be used for risk stratification in this population.

When we analysed independent predictors for 12-month mortality in decompensated patients, MELD, sodium and IMATI were the only significant independent factors in multivariate analysis. A model containing MELD, sodium and IMATI could predict 12month mortality with an AUROC of 0.94 vs. 0.84 for MELD and 0.86 for MELD-Na, indicating that myosteatosis, as previously described ${ }^{24}$ has an independent association with mortality in decompensated cirrhosis (Figure 2).

We grant there are some important limitations of our study. Although this is the largest study evaluating hepatic haemodynamics and all body composition compartments in patients with cirrhosis, it is single-centred and the population size remains limited with a subsequently small number of events. The small sample size 
also limited subgroup analysis in compensated and decompensated patients. The retrospective study design and the indication for performing HVPG measurement and CT scan may introduce selection biases. The prevalence of sarcopenia was also considerably higher in our population than that previously reported for patients on transplant waiting list). ${ }^{20}$ Another limitation is the absence of functional muscle tests and other tests of global nutritional assessment in our patients' evaluation. Additionally, as dry weight measurements were not available in patients with ascites, this could preclude from calculating correct BMI.

In conclusion, our study shows that adipose tissue compartments, but not musclerelated imaging markers correlate with the HVPG. In addition, reduction of subcutaneous adipose tissue deposits and increase in myosteatosis are significantly associated with the development of liver-related decompensation and death. Taking into consideration previous findings ${ }^{25,26}$, both skeletal muscle and fat tissue compartments seem to play a crucial role in the prognostic assessment of patients with cirrhosis. Nevertheless, given the retrospective nature and small sample size, its impact on prognosis must be interpreted cautiously. Mechanistic studies addressing the interplay between liver, muscle and fat tissue in cirrhosis are needed. Furthermore, larger, prospective studies are required to evaluate the impact these factors play on prognosis. Although our results suggest that CT-based body composition assessment including subcutaneous, visceral and intramuscular fat, in addition to muscle ${ }^{5}$, allows risk stratification in cirrhosis. The added benefit of such an approach requires further validation weighted against already substantiated prognostic markers. 


\section{References:}

1. Garcia-Tsao G, Abraldes JG, Berzigotti A, et al. AASLD Practice Guidelines: Portal Hypertensive Bleeding in Cirrhosis: Risk Stratification, Diagnosis, and Management. Hepatology 2017;65(1):310-335.

2. Bosch J, Abraldes JG, Berzigotti A, et al. The clinical use of HVPG measurements in chronic liver disease. Nat Rev Gastroenterol Hepatol 2009;6:573-582.

3. Ripoll C, Groszmann R, Garcia-Tsao G, et al. Hepatic Venous Pressure Gradient Predicts Clinical Decompensation in Patients With Compensated Cirrhosis. Gastroenterology 2007;133:481-488.

4. Ripoll C, Bañares R, Rincón D, et al. Influence of hepatic venous pressure gradient on the prediction of survival of patients with cirrhosis in the MELD era. Hepatology 2005;42(4):793-801.

5. European Association for the Study of the Liver. EASL Clinical Practice Guidelines on nutrition in chronic liver disease. J Hepatol 2019;70(1):172-193.

6. Montano-Loza AJ, Meza-Junco J, Prado CMM, et al. Muscle Wasting Is Associated With Mortality in Patients With Cirrhosis. Clin Gastroenterol H 2012;10:166-U4.

7. Mitsiopoulos N, Baumgartner RN, Heymsfield SB, et al. Cadaver validation of skeletal muscle measurement by magnetic resonance imaging and computerized tomography. J Appl Physiol (1985) 1998;85:115-122.

8. Kvist H, Sjostrom L, Tylen U. Adipose tissue volume determinations in women by computed tomography: technical considerations. IntJ Obes 1986;10(1):5367.

9. Shen W, Punyanitya M, Wang Z, et al. Total body skeletal muscle and adipose tissue volumes: estimation from a single abdominal cross-sectional image. J Appl Physiol (1985) 2004;97:2333-2338.

10. Rossner S, Bo WJ, Hiltbrandt E, et al. Adipose tissue determinations in cadavers--a comparison between cross-sectional planimetry and computed tomography. Int J Obes 1990;14(10):893-902.

11. Irving BA, Weltman JY, Brock DW, et al. NIH ImageJ and Slice-O-Matic computed tomography imaging software to quantify soft tissue. Obesity 2007;15(2):370-6. 
12. Dasarathy J, Alkhouri N, Dasarathy S. Changes in body composition after transjugular intrahepatic portosystemic stent in cirrhosis: A critical review of literature. Liver Int 2011;31(9):1250-8.

13. Durand F, Buyse S, Francoz C, et al. Prognostic value of muscle atrophy in cirrhosis using psoas muscle thickness on computed tomography. J Hepatol 2014;60:1151-1157.

14. Kalafateli M, Mantzoukis K, Choi Yau Y, et al. Malnutrition and sarcopenia predict post-liver transplantation outcomes independently of the Model for Endstage Liver Disease score. J Cachexia Sarcopenia Muscle 2017;8(1):113-121.

15. Ebadi $\mathrm{M}$, Tandon $\mathrm{P}$, Moctezuma-Velazquez $\mathrm{C}$, et al. Low subcutaneous adiposity associates with higher mortality in female patients with cirrhosis. $J$ Hepatol 2018;69(3):608-616.

16. Mehta G, Gustot T, Mookerjee RP, et al. Inflammation and portal hypertension - The undiscovered country. J Hepatol 2014;61(1):155-63.

17. Kim BK, Han KH, Park JY, et al. A liver stiffness measurement-based, noninvasive prediction model for high-risk esophageal varices in B-viral liver cirrhosis. Am J Gastroenterol 2010;105(6):1382-90.

18. Hari A, Nair HK, De Gottardi A, et al. Diagnostic hepatic haemodynamic techniques: safety and radiation exposure. Liver Int 2017;37(1):148-154.

19. Gallagher D, Kuznia P, Heshka S, et al. Adipose tissue in muscle: A novel depot similar in size to visceral adipose tissue. Am J Clin Nutr 2005;81(4):90310.

20. Carey EJ, Lai JC, Wang CW, et al. A multicenter study to define sarcopenia in patients with end-stage liver disease. Liver Transpl 2017;23:625-633.

21. Peduzzi $P$, Concato J, Feinstein AR, et al. Importance of events per independent variable in proportional hazards regression analysis II. Accuracy and precision of regression estimates. J Clin Epidemiol 1995;48(12):1503-10.

22. Kim TY, Kim MY, Sohn JH, et al. Sarcopenia as a useful predictor for longterm mortality in cirrhotic patients with ascites. J Korean Med Sci 2014;29(9):1253-9.

23. Kang SH, Jeong WK, Baik SK, et al. Impact of sarcopenia on prognostic value of cirrhosis: going beyond the hepatic venous pressure gradient and MELD score. J Cachexia Sarcopenia Muscle 2018;9(5):860-870.

24. Montano-Loza AJ, Angulo P, Meza-Junco J, et al. Sarcopenic obesity and 
myosteatosis are associated with higher mortality in patients with cirrhosis. $\mathrm{J}$ Cachexia Sarcopenia Muscle 2016;7:126-135.

25. Ebadi M, Martin L, Ghosh S, et al. Subcutaneous adiposity is an independent predictor of mortality in cancer patients. Br J Cancer 2017;117(1):148-155.

26. Caan BJ, Cespedes Feliciano EM, et al. The importance of body composition in explaining the overweight paradox in cancer. Cancer Res 2018;78(8):19061912

27. Antoun S, Bayar A, lleana E, et al. High subcutaneous adipose tissue predicts the prognosis in metastatic castration-resistant prostate cancer patients in post chemotherapy setting. Eur J Cancer 2015;51:2570-2577.

28. Ishikawa K, Takahashi $\mathrm{K}$, Bujo $\mathrm{H}$, et al. Subcutaneous fat modulates insulin sensitivity in mice by regulating TNF- $\alpha$ expression in visceral fat. Horm Metab Res 2006;38(10):631-8.

29. Delgado MG, Gracia-Sancho J, Marrone G, et al. Leptin receptor blockade reduces intrahepatic vascular resistance and portal pressure in an experimental model of rat liver cirrhosis. AJP Gastrointest Liver Physiol 2013;305(7):G496-502.

30. Erice E, Llop E, Berzigotti A, et al. Insulin resistance in patients with cirrhosis and portal hypertension. AJP Gastrointest Liver Physiol. 2012;302(12):G145865.

31. Berzigotti A, Albillos A, Villanueva C, et al. Effects of an intensive lifestyle intervention program on portal hypertension in patients with cirrhosis and obesity: The SportDiet study. Hepatology 2017;65(4):1293-1305. 
Table 1. Baseline clinical, demographic, laboratory and imaging characteristics of the cohort by gender at HVPG/Body composition evaluation.

\begin{tabular}{|c|c|c|c|c|}
\hline ra & All $(\mathrm{N}=84)$ & Male $(n=51)$ & Female $(n=33)$ & P-value \\
\hline Age (years), mean $\pm S D$ & $57 \pm 11$ & $59 \pm 11$ & $55 \pm 12$ & 0.12 \\
\hline Aetiology n (\%) & & & & \\
\hline Alcohol-related & $43(51.2)$ & $30(58.8)$ & $13(39.4)$ & 0.08 \\
\hline Non-alcoholic fatty liver disease (NAFLD)-related & $20(23.8)$ & $11(21.6)$ & $9(27.3)$ & 0.55 \\
\hline Hepatitis C & $11(13.1)$ & $4(7.8)$ & $7(21.2)$ & 0.08 \\
\hline Autoimmune (Al) liver disease & $6(7.1)$ & $2(4)$ & $4(12.1)$ & 0.15 \\
\hline Hepatitis B & $1(1.2)$ & $1(2)$ & - & - \\
\hline Other & $3(3.6)$ & $3(5.8)$ & - & - \\
\hline Decompensated at HVPG n (\%) & $46(55)$ & $30(59)$ & $16(48)$ & 0.24 \\
\hline MELD score, mean $\pm S D$ & $13 \pm 8$ & $14 \pm 9$ & $12 \pm 7$ & 0.20 \\
\hline Child-Pugh score, mean $\pm S D$ & $7 \pm 2$ & $7.5 \pm 2$ & $7 \pm 2$ & 0.72 \\
\hline Albumin (g/L, 35-52), mean $\pm S D$ & $29.5 \pm 6$ & $30 \pm 6$ & $29 \pm 6.5$ & 0.33 \\
\hline Sodium (mmol/L, 136-145), mean $\pm S D$ & $138 \pm 4$ & $139 \pm 4$ & $138 \pm 4$ & 0.31 \\
\hline Creatinine ( $\mu \mathrm{mol} / \mathrm{L}, 59-104)$, median (IQR) & $73(60-94)$ & $80(68-99)$ & $60(51-74)$ & 0.001 \\
\hline Platelet count (G/L, 150-450), mean $\pm S D$ & $125 \pm 67$ & $117 \pm 65$ & $139 \pm 68$ & 0.13 \\
\hline Liver stiffness (kPa), median (IQR) & $35 \pm 23$ & $37 \pm 23$ & $31 \pm 24$ & 0.40 \\
\hline HVPG $(\mathrm{mmHg})$, mean $\pm \mathrm{SD}$ & $14 \pm 6.3$ & $14.5 \pm 6.3$ & $13.3 \pm 6.3$ & 0.39 \\
\hline Diabetes n (\%) & $25(30)$ & $16(31)$ & $9(27)$ & 0.81 \\
\hline CSPH n (\%) & $63(75)$ & $40(78)$ & $23(70)$ & 0.54 \\
\hline Varices n (\%) & $45(54)$ & $28(55)$ & $17(52)$ & 0.84 \\
\hline Ascites n (\%) & $32(38)$ & $22(43)$ & $10(30)$ & 0.26 \\
\hline Mild & 8 & 4 & 4 & \\
\hline Hepatic encephalopathy n (\%) & $8(10)$ & $5(10)$ & $3(9)$ & 0.91 \\
\hline Beta-blockers n (\%) & $41(49)$ & $26(51)$ & $15(46)$ & 0.66 \\
\hline Statins n (\%) & $15(18)$ & $8(16)$ & $7(21)$ & 0.57 \\
\hline Diuretics n (\%) & $35(42)$ & $22(43)$ & $13(39)$ & 0.82 \\
\hline Death in follow-up n (\%) & $16(19)$ & $12(24)$ & $4(12)$ & 0.26 \\
\hline Episode of decompensation in follow-up n (\%): & $43(51)$ & $25(49)$ & $18(55)$ & 0.89 \\
\hline
\end{tabular}

This article is protected by copyright. All rights reserved. 
HVPG, hepatic venous pressure gradient; CSPH, clinically significant portal hypertension; SD, standard deviation; IQR, interquartile range 
Table 2. Correlations between HVPG and body composition parameters, stratified by gender, sarcopenia, disease stage and aetiology

\begin{tabular}{|c|c|c|c|c|c|c|c|c|}
\hline & $\begin{array}{l}\text { Correlation } \\
\text { of HVPG } \\
\& \text { BMI } \\
\text { (P-value) }\end{array}$ & $\begin{array}{l}\text { Correlation } \\
\text { of HVPG \& } \\
\text { SMI } \\
\text { (P-value) }\end{array}$ & $\begin{array}{l}\text { Correlation } \\
\text { of HVPG \& } \\
\text { PMI (P- } \\
\text { value) }\end{array}$ & $\begin{array}{l}\text { Correlation } \\
\text { of HVPG \& } \\
\text { TATI } \\
\text { (P-value) }\end{array}$ & $\begin{array}{l}\text { Correlation } \\
\text { of HVPG \& } \\
\text { VATI } \\
\text { (P-value) }\end{array}$ & $\begin{array}{l}\text { Correlation } \\
\text { of HVPG \& } \\
\text { SATI } \\
\text { (P-value) }\end{array}$ & $\begin{array}{l}\text { Correlation } \\
\text { of HVPG \& } \\
\text { IMATI } \\
\text { (P-value) }\end{array}$ & $\begin{array}{l}\text { Correlation } \\
\text { of HVPG \& } \\
\text { SATI/VATI } \\
\text { (P-value) }\end{array}$ \\
\hline Overall & $\begin{array}{l}-0.16 \\
(0.15)\end{array}$ & $\begin{array}{l}-0.006 \\
(0.96)\end{array}$ & $\begin{array}{l}-0.003 \\
(0.98)\end{array}$ & $\begin{array}{l}-0.22 \\
(0.045)\end{array}$ & $\begin{array}{l}-0.07 \\
(0.55)\end{array}$ & $\begin{array}{l}-0.28 \\
(\mathbf{0 . 0 1})\end{array}$ & $\begin{array}{l}-0.05 \\
(0.67)\end{array}$ & $\begin{array}{l}-0.24 \\
(\mathbf{0 . 0 3})\end{array}$ \\
\hline Female $(n=33)$ & $\begin{array}{l}-0.36 \\
(0.04)\end{array}$ & $\begin{array}{l}-0.30 \\
(0.09)\end{array}$ & $\begin{array}{l}-0.29 \\
(0.10)\end{array}$ & $\begin{array}{l}-0.26 \\
(0.14) \\
\end{array}$ & $\begin{array}{l}-0.03 \\
(0.89) \\
\end{array}$ & $\begin{array}{l}-0.38 \\
(0.03) \\
\end{array}$ & $\begin{array}{l}-0.03 \\
(0.87) \\
\end{array}$ & $\begin{array}{l}-0.21 \\
(0.25) \\
\end{array}$ \\
\hline Male $(n=51)$ & $\begin{array}{l}-0.06 \\
(0.68)\end{array}$ & $\begin{array}{l}-0.08 \\
(0.6)\end{array}$ & $\begin{array}{l}0.08 \\
(0.60)\end{array}$ & $\begin{array}{l}-0.22 \\
(0.12)\end{array}$ & $\begin{array}{l}-0.15 \\
(0.3)\end{array}$ & $\begin{array}{l}-0.22 \\
(0.12)\end{array}$ & $\begin{array}{l}-0.07 \\
(0.63)\end{array}$ & $\begin{array}{l}-0.25 \\
(0.08)\end{array}$ \\
\hline $\begin{array}{l}\text { Sarcopenia } \\
(n=50)\end{array}$ & $\begin{array}{l}-0.26 \\
(0.07)\end{array}$ & - & - & $\begin{array}{l}-0.29 \\
(\mathbf{0 . 0 4})\end{array}$ & $\begin{array}{l}-0.26 \\
(0.07)\end{array}$ & $\begin{array}{l}-0.24 \\
(0.1)\end{array}$ & $\begin{array}{l}-0.15 \\
(0.29)\end{array}$ & $\begin{array}{l}-0.10 \\
(0.52)\end{array}$ \\
\hline $\begin{array}{l}\text { No } \\
\text { sarcopenia } \\
(n=34)\end{array}$ & $\begin{array}{l}0.05 \\
(0.79)\end{array}$ & - & - & $\begin{array}{l}-0.06 \\
(0.74)\end{array}$ & $\begin{array}{l}0.29 \\
(0.09)\end{array}$ & $\begin{array}{l}-0.30 \\
(0.09)\end{array}$ & $\begin{array}{l}0.1 \\
(0.58)\end{array}$ & $\begin{array}{l}-0.47 \\
(0.006)\end{array}$ \\
\hline $\begin{array}{l}\text { Compensated } \\
(\mathrm{n}=38)\end{array}$ & $\begin{array}{l}0.008 \\
(0.96)\end{array}$ & $\begin{array}{l}0.28 \\
(0.09)\end{array}$ & $\begin{array}{l}0.28 \\
(0.09)\end{array}$ & $\begin{array}{l}-0.068 \\
(0.68)\end{array}$ & $\begin{array}{l}-0.062 \\
(0.71)\end{array}$ & $\begin{array}{l}-0.06 \\
(0.73) \\
\end{array}$ & $\begin{array}{l}-0.172 \\
(0.30)\end{array}$ & $\begin{array}{l}0.044 \\
(0.79)\end{array}$ \\
\hline $\begin{array}{l}\text { Decompens. } \\
(n=46)\end{array}$ & $\begin{array}{l}-0.027 \\
(0.86)\end{array}$ & $\begin{array}{l}-0.035 \\
(0.82)\end{array}$ & $\begin{array}{l}-0.04 \\
(0.81)\end{array}$ & $\begin{array}{l}-0.18 \\
(0.24)\end{array}$ & $\begin{array}{l}0.058 \\
(0.70)\end{array}$ & $\begin{array}{l}-0.305 \\
(\mathbf{0 . 0 4})\end{array}$ & $\begin{array}{l}0.018 \\
(0.91)\end{array}$ & $\begin{array}{l}-0.316 \\
(\mathbf{0 . 0 4 )}\end{array}$ \\
\hline $\begin{array}{l}\text { ALD or } \\
\text { NAFLD cause } \\
(\mathrm{n}=63)\end{array}$ & $\begin{array}{l}-0.16 \\
(0.21)\end{array}$ & $\begin{array}{l}0.041 \\
(0.75)\end{array}$ & $\begin{array}{l}0.045 \\
(0.73)\end{array}$ & $\begin{array}{l}-0.252 \\
(0.048)\end{array}$ & $\begin{array}{l}-0.122 \\
(0.34)\end{array}$ & $\begin{array}{l}-0.28 \\
(0.03)\end{array}$ & $\begin{array}{l}-0.098 \\
(0.45)\end{array}$ & $\begin{array}{l}-0.233 \\
(0.068)\end{array}$ \\
\hline $\begin{array}{l}\text { Other } \\
\text { aetiology } \\
(\mathrm{n}=21)\end{array}$ & $\begin{array}{l}-0.081 \\
(0.73)\end{array}$ & $\begin{array}{l}-0.137 \\
(0.56)\end{array}$ & $\begin{array}{l}-0.271 \\
(0.23)\end{array}$ & $\begin{array}{l}-0.183 \\
(0.43)\end{array}$ & $\begin{array}{l}-0.012 \\
(0.96)\end{array}$ & $\begin{array}{l}-0.287 \\
(0.21)\end{array}$ & $\begin{array}{l}0.048 \\
(0.84)\end{array}$ & $\begin{array}{l}0.055 \\
(0.81)\end{array}$ \\
\hline
\end{tabular}

HVPG, hepatic venous pressure gradient; BMI, body mass index; SMI, skeletal muscle index; PMI, psoas muscle index; TATI, total adipose tissue index; VATI, visceral adipose tissue index; SATI, subcutaneous adipose tissue index; IMATI, intramuscular adipose tissue index; ALD, alcoholic liver disease; NAFLD, nonalcoholic fatty liver disease 
Table 3. Body composition parameters according to degree of portal pressure (HVPG). * $p=0.028$ vs. $<10 \mathrm{mmHg}$.

\begin{tabular}{|c|c|c|c|c|}
\hline & $\begin{array}{l}<10 \mathrm{~mm} \mathrm{Hg} \\
(\mathrm{n}=21)\end{array}$ & $\begin{array}{l}10-12 \mathrm{~mm} \mathrm{Hg} \\
(\mathrm{n}=11)\end{array}$ & $\begin{array}{l}13-15 \mathrm{~mm} \mathrm{Hg} \\
(n=25)\end{array}$ & $\begin{array}{l}\geq 16 \mathrm{~mm} \mathrm{Hg} \\
(\mathrm{n}=28)\end{array}$ \\
\hline BMI $\left(\mathbf{k g} / \mathrm{m}^{2}\right)$ & $30 \pm 7$ & $28 \pm 4$ & $27 \pm 5$ & $28 \pm 5$ \\
\hline $\begin{array}{l}\text { SMI } \\
\left(\mathrm{cm}^{2} / \mathrm{m}^{2}\right)\end{array}$ & $44 \pm 9$ & $44 \pm 8$ & $43 \pm 11$ & $46 \pm 13$ \\
\hline $\begin{array}{l}\mathrm{PMI} \\
\left(\mathrm{cm}^{2} / \mathrm{m}^{2}\right)\end{array}$ & $4.4 \pm 0.9$ & $4.5 \pm 0.8$ & $4.3 \pm 1.1$ & $4.6 \pm 1.3$ \\
\hline $\begin{array}{l}\text { TATI } \\
\left(\mathrm{cm}^{2} / \mathrm{m}^{2}\right)\end{array}$ & $162 \pm 79$ & $143 \pm 37$ & $137 \pm 77$ & $132 \pm 47$ \\
\hline $\begin{array}{l}\text { VATI } \\
\left(\mathrm{cm}^{2} / \mathrm{m}^{2}\right)\end{array}$ & $67 \pm 40$ & $63 \pm 22$ & $53 \pm 8$ & $65 \pm 32$ \\
\hline $\begin{array}{l}\text { SATI } \\
\left(\mathrm{cm}^{2} / \mathrm{m}^{2}\right)\end{array}$ & $91 \pm 47$ & $77 \pm 24$ & $79 \pm 51$ & $65 \pm 33^{*}$ \\
\hline $\begin{array}{l}\text { IMATI } \\
\left(\mathrm{cm}^{2} / \mathbf{m}^{2}\right) \dagger\end{array}$ & $3.5(1.2-4.2)$ & $3.0(0.98-3.7)$ & $2.6(0.6-4.4)$ & $2.6(1.2-3.8)$ \\
\hline SATI/VATI $\dagger$ & $1.4(0.81-1.97)$ & $1.1(0.9-1.3)$ & $1.5(0.7-2.9)$ & $0.9(0.6-1.6)$ \\
\hline
\end{tabular}

BMI, body mass index; SMI, skeletal muscle index; PMI, psoas muscle index; TATI, total adipose tissue index; VATI, visceral adipose tissue index; SATI, subcutaneous adipose tissue index; IMATI, intramuscular adipose tissue index; †expressed in median (IQR) 
Table 4. Univariate Cox regression analysis of factors predicting 12-month decompensation in compensated patients

\begin{tabular}{|c|c|c|}
\hline \multirow[t]{2}{*}{ Characteristics } & \multicolumn{2}{|c|}{$\begin{array}{l}\text { Compensated }(n=38) \\
\text { Events (decompensation) } n=7\end{array}$} \\
\hline & $\begin{array}{l}\text { Univariate HR } \\
\quad(95 \% \mathrm{Cl})\end{array}$ & P- value \\
\hline Age & $0.96(0.90-1.03)$ & 0.27 \\
\hline Gender & $0.65(0.145-2.93)$ & 0.58 \\
\hline ALD/NAFLD vs. others & $1.71(0.38-7.8)$ & 0.48 \\
\hline Albumin & $0.97(0.83-1.21)$ & 0.65 \\
\hline Bilirubin & $1.01(0.97-1.04)$ & 0.72 \\
\hline Sodium & $1.02(0.82-1.27)$ & 0.83 \\
\hline Creatinine & $0.97(0.92-1.02)$ & 0.20 \\
\hline Platelet count & $0.985(0.97-1.001)$ & 0.07 \\
\hline Diabetes & $2.62(0.31-22.1)$ & 0.38 \\
\hline CSPH & $4.78(0.58-39.7)$ & 0.15 \\
\hline Varices & $2.29(0.44-11.9)$ & 0.33 \\
\hline HVPG & $1.12(0.99-1.26)$ & 0.08 \\
\hline Child-Pugh score & $1.01(0.56-1.8)$ & 0.98 \\
\hline MELD score & $1.1(0.85-1.41)$ & 0.48 \\
\hline MELD SATI score & 1.03 (0.93-1.13) & 0.60 \\
\hline Liver stiffness & $1.03(0.998-1.07)$ & 0.06 \\
\hline Spleen size & $1.17(0.95-1.44)$ & 0.15 \\
\hline LSPS & $1.26(1.05-1.51)$ & 0.013 \\
\hline BMI & $0.94(0.79-1.11)$ & 0.44 \\
\hline SMI & $0.97(0.89-1.05)$ & 0.45 \\
\hline PMI & $0.74(0.33-1.69)$ & 0.48 \\
\hline TATI & $0.98(0.96-1.0003)$ & 0.09 \\
\hline VATI & $0.94(0.90-0.99)$ & 0.01 \\
\hline SATI & $0.99(0.98-1.01)$ & 0.71 \\
\hline IMATI & $0.69(0.38-1.24)$ & 0.21 \\
\hline SATI/VATI & $1.75(1.2-2.5)$ & 0.002 \\
\hline
\end{tabular}

LSPS, liver stiffness-spleen size over platelet score; HVPG, hepatic venous pressure gradient; BMI, body mass index; SMI, skeletal muscle index; PMI, psoas muscle index; TATI, total adipose tissue index; VATI, visceral adipose tissue index; SATI, subcutaneous adipose tissue index; IMATI, intramuscular adipose tissue index; ALD, alcoholic liver disease; NAFLD, non-alcoholic fatty liver disease

This article is protected by copyright. All rights reserved. 


\section{Figure legends}

Figure 1. Abdominal CT images at the 3rd. lumbar vertebra of two female patients with cirrhosis applied for body composition assessment. Patient A had alcoholic liver disease, MELD 9, HVPG $16 \mathrm{~mm} \mathrm{Hg}$ and low SATI (43 cm2/m2), Patient B had alcoholic liver disease, MELD 8, HVPG 9 mm Hg and high SATI $(84 \mathrm{~cm} 2 / \mathrm{m} 2)$. Subcutaneous adipose tissue is shown in blue and visceral adipose tissue in yellow. Figure 2. (A) AUROC for liver stiffness, APRI, HVPG, LSPS and LSPS-TATI for predicting 12-month decompensation in compensated patients; (B) AUROC for MELD-sodium-IMATI to detect 12-month mortality in decompensated patients

Supplementary Figure 1. Flowchart of patients submitted to hepatic haemodynamics included for the body composition analyses 

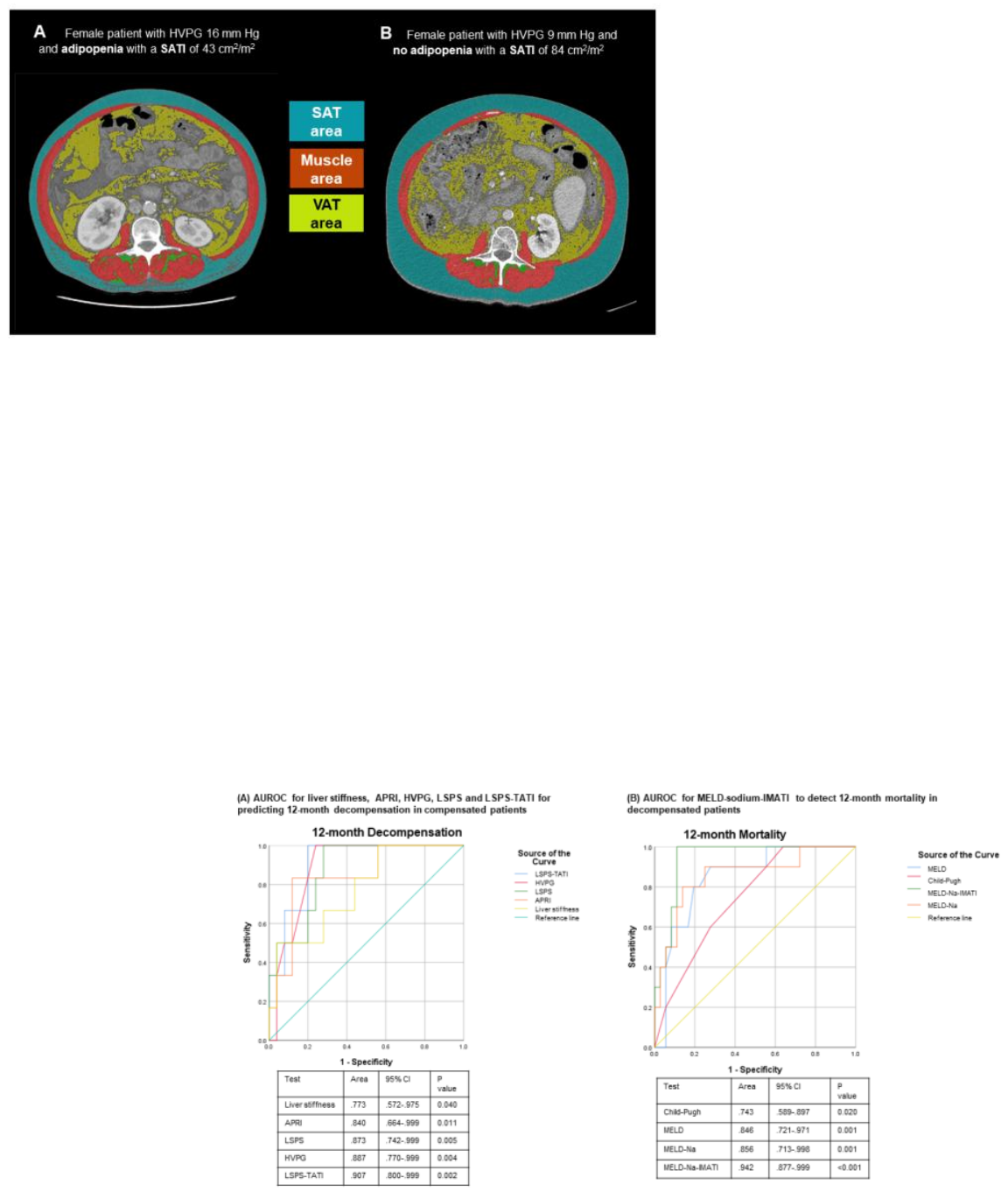

This article is protected by copyright. All rights reserved. 